\title{
Profile Interview: Prof. Terrie Taylor
}

"Every malaria fever should be treated quickly. That's where I would put my money. Maybe we will get on top of transmission, maybe we will get on top of mosquitoes but in the meantime, let us stop children from dying".

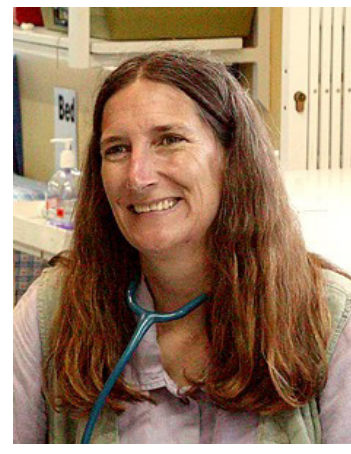

”Dr. Yohane Gadama (YG), MMJ Intern and Mr. Elias Phiri (EP), MMJ volunteer talks to Prof Terrie Taylor (TT) on her personal background, her role in Malaria research and the current work she is doing, and the March for Science campaigns that she has been championing.

YG: Tell us about your personal and professional background?

TT: I was born and raised in Traverse City, Michigan (USA). My father was a general practitioner and that influenced my interest in medicine from an early age. In 1973, I went to Swarthmore College where I did a bachelor's degree, majoring in biology before I went to Chicago College of Osteopathic Medicine. I had my medical training there, and graduated with a D.O. degree in 1981. I must mention that my undergraduate training at Swarthmore was very profound as it had an aspect of discovery, which I think ignited my interest in research. After completing my training in Chicago, I did my internship, a general rotating internship as one does in Malawi, back in Michigan at Riverside Osteopathic Hospital. Throughout internship, I still had not decided on what I wanted to do I'd thought I would be a GP like my dad, but was beginning to change my mind. While still giving myself time to decide, through the help of the Dean at the College of Osteopathic Medicine at Michigan University, I ended up working in Sudan for one year - that was pivotal because I could see, first hand, the value of biomedical research in resourcechallenged settings. I then moved back to USA and did my internal medicine residency at Detroit Osteopathic Hospital. Upon completing my internal medicine residency in 1985, I decided to strengthen my tropical medicine knowledge so I went to Liverpool School of Tropical Medicine where I did a Masters in Tropical Medicine. The Dean at MSU-COM met with me before I went to Liverpool --- he had a vision of global health well before it became trendy, and he told me that if I returned to Michigan State with a research project in a developing country that would be hospitable to Michigan State medical students, he would give me a job.

YG: How did you end up working in Malawi and in Malaria research precisely?

TT: While at Liverpool School of Tropical Medicine, I met Prof. Malcolm Molyneux who was working there. By then, he had spent 10 years in Malawi and has established himself as a brilliant, hardworking young physician. His connections supported a lot of Masters Students projects, and because of that, I came to Malawi in 1986, and worked with Gilbert Burnham at Malamulo Hospital. Before Malcolm came to supervise us, he had a conversation with Ministry of health $(\mathrm{MoH})$ officials. $\mathrm{MoH}$ advised Malcolm that their top research priority was severe malaria in children. Malcolm and I agreed to team up - but because we were both internal medicine physicians, we had to partner with a pediatrician. Luckily, Dr. Mrs. Borgstein welcomed us into her department at Queen Elizabeth Central Correspondence:

Hospital and that's how we (mmj@medcol.mw) ended up in Blantyre and Mrs. Prof Borgstein became https://dx.doi.org/10.4314/mmj.v30i2.16 involved.

$Y G$ : From that background, it seems your stay in Malawi is even older than College of Medicine, what has been your milestones in Malawi?

TT: It has been 31 years, so I like to think of it in decades. 1 st decade - Intensive clinical observation of malaria patients on the bedside. During this period, we developed the Blantyre Coma Score (BCS), worked out the importance of low blood sugar, lactic acidosis, the pharmacokinetics of quinine. But all along, our fundamental question was, "Why are children dying?'. At the end of 10 years, we still didn't know but about 2 in every 3 patients, the mode of death was very stereotypical: mom starts to cry, nurse observes erratic breathing pattern, nurse calls a doctor, child gasping, resuscitation attempted but not successful. At that point, Malcolm and I thought that the brains of these children were herniating but we couldn't prove it.

2nd decade - Autopsy decade. We were looking for the typical features of herniation in these deaths from severe malaria. From these studies, we learnt that $30-40 \%$ of children labelled to have cerebral malaria did not actually have cerebral malaria. Yes, they were infected with malaria parasites, yes, they were in coma, but the two were not linked. In that sense, we were now beginning to make sense of the findings from our ophthalmology colleagues who were making fascinating observations in the retinas of children who met the clinical case definition of cerebral malaria. With the autopsies, the retina findings made sense. Patients with retinopathy had cerebral microvasculature infected with parasites, and patients with normal eye exams did not. This piece of information was very important in terms of classifying patients more accurately.

3rd Decade - Neuroimaging decade. The MRI came to Malawi in 2008. From this decade, we established a strong association between increase in brain volume and herniation and death. If not for the MRI, we could not have established this fact. And in addition to our research, the MRI has become very beneficial to managing patients in Malawi.

4th decade - Intervention decade. We can't say brain swelling causes death because all we have is an association. To clearly say brain swelling causes death, we have to intervene and show that lives can be saved. That's why we are now doing the interventional clinical trial using the paeditriac intensive care unit to close this circle. 
$E P$ : Briefly, tell us what this trial is all about?

TT: We have two interventions that we are trying:

1- Ventilatory support. All the children who die stop breathing --- but in those who survive, the increased brain volume resolves quickly. So the thinking is that maybe if
we can breathe for these children, with a ventilatory, and le we can breathe for these children, with
nature take its course, they will recover.

2- Using osmotic agents, in our study, hypertonic saline, to reduce the cerebral oedema. The third arm of the trial is receiving the standard care.

YG: How do you envision the findings from this trial to influence clinical practice?

TT: I should say it is difficult to know until we know what works. There are a couple of challenges, one being swelling and eventually at risk of dying. At the moment we swelling and eventually at tisk of dyng. At the moment we by many in maria-endemic areas. While we acessible he the $\mathrm{Mn}$, we are also investigating other measures, other re able to identify surrogate markers, then clinicins identify children at high risk and institute appropriate care immediately including referring them to tertiary institutions. I m confident that once we identify the intervention the works, we will be able to make it feasible in our setting.

YG: There has been criticism from other circles, including policy makers that much of science (research) being done is not being translated on the ground to offset the malaria burden. What is your take on this?

$T T$ : I accept that criticism. I think one has to take a wide view. When we initially had the discussion with $\mathrm{MoH}$, their research priority was severe malaria in children. That is what we started, that is what we are good at and that is our skill set. There are colleagues like Don Mathanga of Malaria Alert Centre who are skilled at epidemiology and community based work. They are the group I think have made significant strides in terms of by combining malaria rapid diagnostic tests (mRDTs) with effective anti-malarials, scaling up distributions of insecticide-treated nets, and other preventive measures. That to me, has had a huge public health benefit. In fact, we are now seeing fewer cerebral malaria patients than before. That being said, I don't think any knowledge wasted. Our work will ultimately enable clinicians to detect early signs of severe cerebral malarla and refer these children to tertiary institution, even if the interventions from ou study may not be readily extrapolated to other settings.

YG: As someone who has been in malaria research for so long, why do you think malaria is still a huge burden in Malawi?

TT: Malaria is a very tricky parasite. It is deeply entrenche here. For many years, we were working at the tip of an iceberg. we have molecular technologies of detecting the parasites, it turns out that man people are infected. These asymptom, people are reservoirs, infecting the mosquitoes. There was no way we could get on-top of malaria by just looking at the sick, under-five children. So we have broadened our scope and now we are working strategically to interrupt the

P:Doyou thinkwe need more research or implementing no far?

$T T:$ Actually we have learnt a lot and one thing we have learn is that there is a huge problem of asymptomatic individuals. Now the question is how to deal with this problem withou engendering resistance among mosquitoes, the parasite and the population. Currently I am working with Dr. Don Mathanga on the project called 'the intransigence of malaria in Malaw - this project addressed this question: "we have thrown nning"?

$E P$ : There is malaria vaccine being tried in Malawi. Do you think this will be our long awaited answer?

TT: I don't know. Again, I think malaria is a very tricky parasite. I always say to medical students that I have not (anged my investment strategy. I am not putting $m y$ (minimal) investments in the malaria vaccine, yet.

YG: So, assuming you had all the money in the world, where would you direct much focus into in the figh against malaria

T:I would directit to eliminating malaria deaths. I am not so much worried about people walking around asymptomatic. m worried with malaria deaths. I think we have made a giant public heath step in pushing the RDTs to community level and paing them with effective artemisinin-based combine therapies (LA). That to me is the way to go. Every malaria fever should be treated quickly. That's where I would put $m y$ money. Maybe we will get on top of transmission, maybe we will get on top of mosquitoes but in the meantime, let us stop children from dying.

$E P$ : You are an internal medicine physician but you work has hanged on pediatric population. How is thi possible?

TT: I think it is the beauty of research, which calls for collaboration. First we were bedside researchers with pediatric collegoues, then we involved pathologits, then phthalmologist, then neuroradiologists and now we ate nvolving the paediatric critical care specialists.

YG: Talking of collaboration, what do you think of organizational collaboration in Malawi at the moment $T T$ : It is very nice and encouraging to have these collaborations developed over the years. There have been mutually beneficial collaborations - I haven't witnessed (E) Everybody has identified their niche and we are able to assist ach other where need be.

EP: Outside malaria world, you have been seen much involved in the 'March for Science' campaigns. What are they about and what is your motivation?

TT: When Donald Trump was elected into office, I was disturbed and worried about his potential impact. Two issues that worried me most were funding for science research and the environment. I thought these were not likely to be our papers. I will try to do better with publishing locally. supported by him. A way to raise awareness for continued think it's because we are always trying for the highest impact support for funding research was to educate the public, and factor possible.

his global campaign is one way to do that. I like 'March for Science' because it raises awareness here in Malawi - and our efforts are multiplied by joining other countries. I hope it will continue.

$E P$ : What are the challenges you face in your work?

TT: I must say Malawi is a wonderful place to work. The colleagues are incredible. The challenge I would mention that is secuing strong issu

unding.

YG: I have noted that you don't publish your result with the local journal, MMJ, and this is the case with many other senior researchers in Malawi. Why is that the case and what do you think MMJ can do to attract senior researchers?

TT: That is a good question as regards to the destination of
YG: Finally, what do you do in your free time?

$T T$ : It depends where I am. As you know, I stay 6 months in Malawi and 6 months in USA every year. When in Malawi, like cycling, baking and hiking on Mt. Mulanje. When in I A, I am a stepmother, a wife and I volunteer in community ssues. 